\title{
Restoration of tissue factor pathway inhibitor inhibits invasion and tumor growth in vitro and in vivo in a malignant meningioma cell line
}

\author{
SHAKUNTALA KONDRAGANTI ${ }^{1}$, CHRISTOPHER S. GONDI ${ }^{1}$, MEENA GUJRATI ${ }^{2}$, \\ IAN McCUTCHEON ${ }^{4}$, DZUNG H. DINH ${ }^{3}$, JASTI S. RAO ${ }^{1,3}$ and WILLIAM C. OLIVERO ${ }^{3}$ \\ ${ }^{1}$ Program of Cancer Biology, Department of Cancer Biology and Pharmacology, \\ Departments of ${ }^{2}$ Pathology and ${ }^{3}$ Neurosurgery, University of Illinois College of Medicine, \\ Peoria, IL; ${ }^{4}$ University of Texas M.D. Anderson Cancer Center, Houston, TX, USA
}

Received December 22, 2005; Accepted February 9, 2006

\begin{abstract}
Tissue factor pathway inhibitor 2 (TFPI-2) is a 32-kDa extracellular matrix-associated kunitz-type serine proteinase inhibitor. It is secreted by all vascular cells and plays a role in tumor invasion and metastasis, presumably by plasmin-mediated matrix remodeling. Previous studies have shown high expression of TFPI-2 by benign tumors and low or absent expression in highly malignant tumors. Malignant meningiomas constitute $10-15 \%$ of all meningiomas and our previous studies revealed loss of expression of TFPI- 2 in malignant gliomas. To investigate the role of TFPI-2 in the invasiveness of malignant meningiomas, we stably transfected the human meningioma cell line, IOMM-Lee, with a vector capable of expressing a transcript complementary to the full length of TFPI- 2 mRNA in a sense orientation. Restoration of TFPI-2 led to decreased invasiveness of transfected cells compared to parental and vector controls in Matrigel and spheroid assays and inhibition of angiogenesis in in vitro cocultures with human umbilical vein endothelial cells (HUVEC) and in vivo dorsal skin assay studies. As assessed by Western blotting, we also observed increased expression of BAX, cytochrome $\mathrm{c}$ and caspase 3 as well as decreased expression of XIAP (X-linked inhibitor of apoptosis). Finally, TFPI-2 overexpression inhibited intracranial tumor formation in nude mice. Our data substantiate our previous observation that TFPI-2 plays an important role in tumor progression and has potential in anti-cancer therapy.
\end{abstract}

Correspondence to: Dr W.C. Olivero, Department of Neurosurgery, University of Illinois College of Medicine, P.O. Box 1649, Peoria, IL 61656, USA

E-mail: olib@uic.edu

Abbreviations: ECM, extracellular matrix; TFPI-2, tissue factor pathway inhibitor; CNS, central nervous system; PBS, phosphatebuffered saline; FITC, fluorescein-isothiocyanate

Key words: TFPI-2, angiogenesis, invasion

\section{Introduction}

Proteolytic degradation of extracellular matrix is an important step in tumor invasion and metastasis. Various proteases, including serine, metallo and cysteine proteinases, are produced by tumor cells and are significantly involved in matrix degradation. TFPI-2 is a serine proteinase inhibitor with broad spectrum inhibitory effects (1-3). Recombinant human TFPI- 2 has been shown to inhibit trypsin, plasmin, chymotrypsin, cathepsin G, plasma kallikrein and factor VIIa, but not urokinase plasminogen activator or tissue plasminogen activator (3-7). It is a $32-\mathrm{kDa}$ serine proteinase inhibitor consisting of three tandemly arranged kunitz-type domains flanked by short acidic amino terminus and a highly basic $\mathrm{C}$ terminal tail $(1,3)$. It is homologous to human TFPI, which is a regulator of extrinsic coagulation pathway. It is secreted by various cells, including endothelial cells, fibroblasts, keratinocytes (5) and syncytiotrophoblasts (8) TFPI-2 is abundantly present in extracellular matrix (75-90\%) (9) and binds to heparin, a glycosaminoglycan, by means of argininemediated ionic interactions (10). The gene is mapped to chromosome 7q22 by fluorescence in situ hybridization (11). TFPI-2 is downregulated during tumor progression in various cancer cell lines, including gliomas $(12,13)$, lung cancer (14), and prostate cancer (15). Previous studies have demonstrated that exogenous TFPI-2 inhibits degradation of fibroblastderived ECM and Matrigel invasion in HT-1080 fibrosarcoma cells by inhibiting plasmin (2). Exogenous recombinant TFPI-2 also inhibits invasiveness of glioblastoma cells as shown by Matrigel assay (13).

Meningiomas are extra-axial primary brain tumors arising from the leptomeninges and arachnoid membrane. They constitute the second most common central nervous system (CNS) tumor, accounting for $22 \%$ of all intracranial tumors. Meningiomas exhibit a wide spectrum of histological patterns ranging from purely fibroblastic to predominantly epithelioid aspects, including the formation of true glandular structures. Most meningiomas are benign. Approximately $10 \%$ are atypical and malignant and, as such, are not completely resectable and tend to recur $(16,17)$. This recurrence is partly due to the invasiveness of these tumors into the brain, duramater and 
bone, thereby resulting in a poor prognosis. Our previous studies have demonstrated that the loss of TFPI-2 is associated with malignancy in gliomas (13) while restoration of TFPI-2 by TFPI-2 mRNA decreases invasiveness in gliomas (15). Here, we report the effects of modulating TFPI-2 expression on the invasive phenotype of meningioma cells in vitro and in vivo. We also studied the molecular mechanisms that regulate angiogenesis in relation to TFPI-2 production using co-cultures of endothelial and meningioma cells in vitro and in vivo.

\section{Materials and methods}

Preparation of constructs and transfection of cells. We used TFPI-2 constructs that were previously prepared in our lab (12). IOMM-Lee cells were transfected with $0.7 \mathrm{~kb}$ sense transcript using lipofectamine (Life Technologies, Gaithersburg, MD). Briefly, cells were grown overnight ( $4 \times 10^{5}$ cells $/ 60-\mathrm{mm}$ dish) and washed twice with PBS. Then, 1-2 $\mu \mathrm{g}$ of plasmid DNA was mixed with $100 \mu \mathrm{l}$ of serum-free medium and $7 \mu \mathrm{l}$ of lipofectamine. Twelve hours later, the medium was replaced with DMEM medium containing $10 \%$ fetal bovine serum. We selected cells $48 \mathrm{~h}$ after transfection by growing the cells

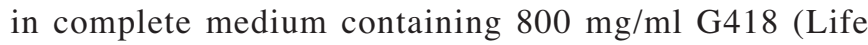
Technologies). After selection, stable transfectants were expanded and used for the studies described.

Cell culture conditions. An established human meningioma cell line, IOMM-Lee (kindly provided by Dr Ian E. McCutcheon, University of Texas M.D. Anderson Cancer Center, Houston, TX), was used in the current study. Cells were maintained in Dulbecco's modified Eagle's medium (Mediatech, Herndon, VA) supplemented with $10 \%$ fetal bovine serum, $100 \mu \mathrm{g} / \mathrm{ml}$ streptomycin and $100 \mathrm{U} / \mathrm{ml}$ penicillin (Invitrogen, Carlsbad, $\mathrm{CA}$ ) in a humidified atmosphere containing $5 \% \mathrm{CO}_{2}$ at $37^{\circ} \mathrm{C}$.

Tissue processing. Fresh human brain tumor samples were collected in the operating room and transferred on ice to a $-80^{\circ} \mathrm{C}$ freezer. Samples were weighed, placed in Tris- $\mathrm{HCl}$ buffer (37.5 mM Tris-HCl, $0.75 \mathrm{mM}$ EDTA, $75 \mathrm{mM} \mathrm{NaCl}$, $15 \mathrm{mM}$ lysine, $\mathrm{pH} 9.5$ ) at a ratio of $50 \mathrm{mg}$ of tissue to $1 \mathrm{ml}$ of buffer and homogenized using a tissue tearer. After centrifugation at $14,000 \mathrm{rpm}$ for $15 \mathrm{~min}$, the pellet was discarded and the supernatant stored at $-80^{\circ} \mathrm{C}$.

Western blotting. Tumor extracts (30 $\mu \mathrm{g})$ were boiled for 35 min and separated on $15 \%$ polyacrylamide gels (18). After electrophoresis, proteins were immunoblotted onto nitrocellulose membranes (19). The membranes were blocked with $6 \%$ milk and probed with anti-TFPI- 2 polyclonal antibody (1:3000 dilution) (kindly provided by Dr Walter Kisiel). Anti-rabbit IgG (H+L) HRP-linked (Biomeda, Foster City, CA) was used as a secondary antibody and membranes were developed according to an enhanced chemiluminescence protocol as per manufacturer's instructions (Amersham, Arlington Heights, IL).

ECM proteins were extracted from cell cultures of parental and sense transfected clones with $200 \mu 1$ of SDS-PAGE sample buffer. Aliquots $(25 \mu 1)$ of these extracts were assayed for TFPI-2 protein levels by Western blotting as described above.
Matrigel invasion assay. In vitro invasion of meningioma cells was measured by the invasion of cells through Matrigelcoated (Collaborative Research Inc., Boston, MA) transwell inserts (Costar, Cambridge, MA) according to a previously described procedure (20). Briefly, 12-well transwell inserts with an 8-mm pore size were coated with a final concentration of $1 \mu \mathrm{g} / \mathrm{ml}$ of Matrigel in cold serum-free DMEM. IOMM-Lee parental and TFPI-2 transfectant cells were trypsinized and $200 \mu 1$ of cell suspension $\left(1 \times 10^{6}\right.$ cells $\left./ \mathrm{ml}\right)$ was added to triplicate wells. After a $24-\mathrm{h}$ incubation period, the cells that passed through the filter into the lower wells were quantitated by counting random fields and expressed as a percentage of the sum of the cells in the upper and lower wells (21).

In vitro angiogenesis. IOMM-Lee parental and TFPI-2-transfected clones $\left(2 \times 10^{4}\right)$ were seeded in 8-well chamber slides (Lab-Tek, Campbell, CA). After 6-8 h, 4x104 human microvascular endothelial cells (HMEC), which were obtained from the Center for Disease Control and Prevention (Atlanta, GA), were co-cultured with IOMM-Lee cells. Seventy-two hours later, cells were fixed and stained with factor VIII antibody followed by staining with FITC-conjugated secondary antibody. Cells were viewed under a fluorescent microscope and the images were quantified for microvascular length using Image Pro-Discovery software.

Dorsal skin fold assay. The dorsal skin fold assay was used to examine in vivo angiogenesis in IOMM-Lee parental and TFPI-2-transfected cells. A chamber consisting of a ring (Millipore, Bedford, MA) was covered with Millipore filters $(0.45-\mu \mathrm{m}$ pore size $)$ on both sides. PBS $(20 \mu \mathrm{l})$ was used to wet the filters and $2 \times 10^{6}$ cells (IOMM-Lee parental and transfected) were suspended in $150 \mu 1$ of serum-free medium or PBS. This final cell suspension was injected into the chambers through the opening in the ring. The opening was sealed with bone wax. Athymic female nude mice were anesthetized by i.p. injection with ketamine $(50 \mathrm{mg} / \mathrm{kg})$ and xylazine $(25 \mathrm{mg} / \mathrm{kg})$ and a dorsal air sac was made by injecting $10 \mathrm{ml}$ of air. The chambers were then placed subcutaneously by making an incision in the air sac and the incision was closed. After 10 days, the implanted chambers were removed and the angiogenic response was assessed under a stereomicroscope (Olympus Optical, Tokyo, Japan) by determining the number of newly formed vessels $>3 \mathrm{~mm}$ with the characteristic zigzagging pattern of tumor cell-induced new vasculature in the s.c. side of the skin area.

Colony formation. IOMM-Lee parental and TFPI-2-transfected cells $\left(4 \times 10^{4}\right)$ were seeded in 100 -mm culture plates (Corning Incorporated, Corning, NY) with serum-containing DMEM and incubated at $37^{\circ} \mathrm{C}$ with humidified air and $5 \% \mathrm{CO}_{2}$. The medium was replaced every third day and, after 2 weeks, the colonies were fixed and stained with Hema 3 (Fisher Diagnostics, Middletown, VA). Colonies were counted under microscope as a measure of clonogenicity.

Intracerebral injection. To examine the in vivo effects of TFPI-2 in meningiomas, we injected $1 \times 10^{6}$ IOMM-Lee parental and TFPI-2 transfected cells intracranially into female nude mice. Cells were trypsinized and resuspended in serum-free 
medium and injected into the brains of athymic female nude mice. Mice were anesthetized with an i.p. injection consisting of $50 \mathrm{mg} / \mathrm{kg}$ ketamine, $25 \mathrm{mg} / \mathrm{kg}$ xylazine and injected intracerebrally with a $10-\mathrm{ml}$ aliquot $\left(1 \times 10^{6}\right)$ of the specified cell type with the aid of a stereotactic frame as described previously (20). After 2 weeks, mice were sacrificed via intracardiac perfusion, first with PBS and then with formaldehyde. Brains were removed, placed in $4 \%$ paraformaldehyde, and embedded in paraffin as per standard protocols. Sections were prepared and stained with H\&E.

Immunoblotting analysis. Total cell lysates were prepared from IOMM-Lee parental and transfected cells by incubating the cells in RIPA buffer $(150 \mathrm{mM} \mathrm{NaCl}, 1 \%$ Triton X-100, $1 \%$ sodium deoxycholate, $0.1 \%$ SDS, $20 \mathrm{mM}$ EDTA and $50 \mathrm{mM}$ Tris, $\mathrm{pH} \mathrm{7.4)} \mathrm{for} 1 \mathrm{~h}$ at $41^{\circ} \mathrm{C}$. In total, 20-50 $\mu \mathrm{g}$ of protein from each sample were subjected to $12 \%$ SDS-PAGE electrophoresis and transferred onto nitrocellulose membranes (Bio-Rad Labs, Hercules, CA). Membranes were blocked with $6 \%$ non-fat dry milk, $0.1 \%$ Tween-20 in PBS for $1 \mathrm{~h}$. The primary antibodies employed were directed against caspase 3 (Cell Signaling Technology, Beverly, MA), cytochrome c (Becton Dickinson Co., San Jose, CA), BAX (Santa Cruz Biotechnology, Santa Cruz, CA), XIAP (Cell Signaling Technology), and GAPDH (Novus Biologicals, Littletown, $\mathrm{CO})$. HRP-conjugated goat anti-mouse $\operatorname{IgM}(\mathrm{H}+\mathrm{L})$ and antirabbit IgG $(\mathrm{H}+\mathrm{L}) \mathrm{HRP}-$ linked (Biomeda, Foster City, CA) were used as secondary antibodies. The membranes were developed according to the manufacturer's instructions (Amersham, Arlington Heights, IL).

\section{Results}

A eukaryotic expression vector, pcDNA 3.1, was used to transfect IOMM-Lee (meningioma) cells with a $0.7-\mathrm{kb}$ sense TFPI-2 cDNA. Stable transfectants were initially grown in $800 \mu \mathrm{g} / \mathrm{ml}$ of $\mathrm{G} 418$ and selected with cloning cylinders after 10-15 days and propagated. No difference was found in the growth rate of parental and transfected clones. Several sense clones with similar expression levels were developed.

TFPI-2 expression in tissue samples. Our previous studies showed that TFPI-2 expression was downregulated or absent in malignant tumors when compared to benign tumors. Consequently, we subjected normal brain, benign and malignant meningioma tumor extracts to SDS-PAGE and analyzed the extracts for TFPI-2 expression using Western blotting with anti-TFPI-2 polyclonal antibody (Fig. 1A). TFPI-2 triplet bands were observed in normal brain and benign meningioma samples but were absent or significantly decreased in malignant meningioma samples (Fig. 1A).

TFPI-2 protein expression in stable transfectants. Studies by Lino et al (9) showed that most (75-90\%) of the TFPI-2 expression is associated with the extracellular matrix. ECM proteins obtained from $80-90 \%$ confluent cultures of parental and stable sense TFPI-2 clones were immunoblotted with anti-TFPI-2 polyclonal antibody. Prominent TFPI-2 triplet bands were observed in TFPI-2-transfected sense clones IOMM-TFPI-2 (4) and IOMM-TFPI-2(6) but were absent in parental and vector controls (Fig. 1B).
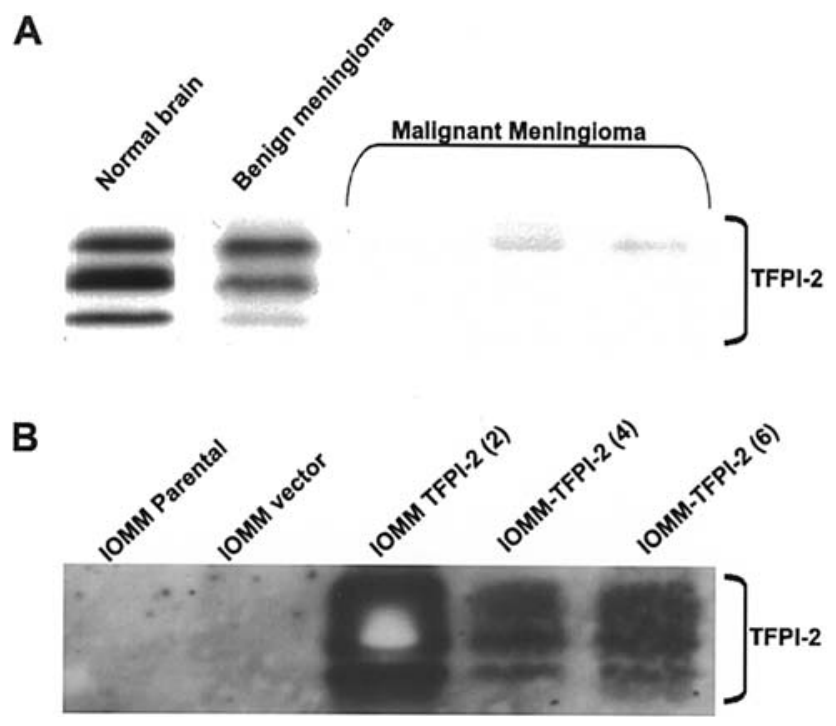

Figure 1. Expression of TFPI-2 in normal brain and meningioma tissue samples. Tissue extracts $(30 \mu \mathrm{g})$ from normal brain and meningioma samples were separated on $15 \%$ SDS-PAGE and immunoblotted with anti-TFPI-2 antibody (A). ECM $(25 \mu 1)$ obtained from $80-90 \%$ confluent cultures of parental and TFPI-2 stable transfectants were subjected to $15 \%$ SDS-PAGE and analyzed for TFPI-2 protein by immunoblotting with TFPI- 2 polyclonal antibody (B).

TFPI-2 inhibits invasion by Matrigel assay. TFPI-2 is a serine proteinase inhibitor that inhibits invasiveness presumably by mediating plasmin. We used a Matrigel assay to determine whether TFPI- 2 restoration would prevent invasion by meningioma cells. Cells $\left(1 \times 10^{6}\right)$ [parental and stable transfectants IOMM-TFPI-2 (4) and IOMM-TFPI-2 (6)] were layered on Matrigel-coated transwell plates and allowed to invade for $24 \mathrm{~h}$. The cells that invaded the lower surface were stained with Hema 3. The staining of IOMM sense clones was less intense as compared to parental cells (Fig. 2A). Quantitative analysis demonstrated that only $38 \%$ and $25 \%$ of IOMM (4) and IOMM-TFPI-2 (6) transfected cells invaded the lower surface in comparison to parental cells (Fig. 2B).

TFPI-2 inhibits in vitro angiogenesis. Angiogenesis, or new vessel formation, is one of the characteristic features of malignant tumors. Our previous studies using SNB19 cells demonstrated reduced tumor growth after TFPI-2 restoration. Here, we studied the effect of TFPI-2 on capillary formation by co-culturing human vascular endothelial cells with IOMMLee cells. After 72 h, the cells were stained with factor VIII (Vonwillebrand factor), a specific marker for endothelial cells, and FITC-conjugated secondary antibody and observed for capillary network formation. As seen in Fig. 3A, capillary network formation is present in parental cells but is reduced or absent in TFPI-2-transfected stable clones IOMM (4) and IOMM-TFPI-2 (6).

TFPI-2 inhibits in vivo angiogenesis. Here, we used the dorsal skin fold assay as an in vivo model to study the effect of TFPI-2 on capillary-like structure formation. We implanted microchambers with parental and transfected stable clones under the skin of nude mice and examined the capillary formation after 10 days. Implanted chambers with parental cells resulted in formation of new vessels as determined by 

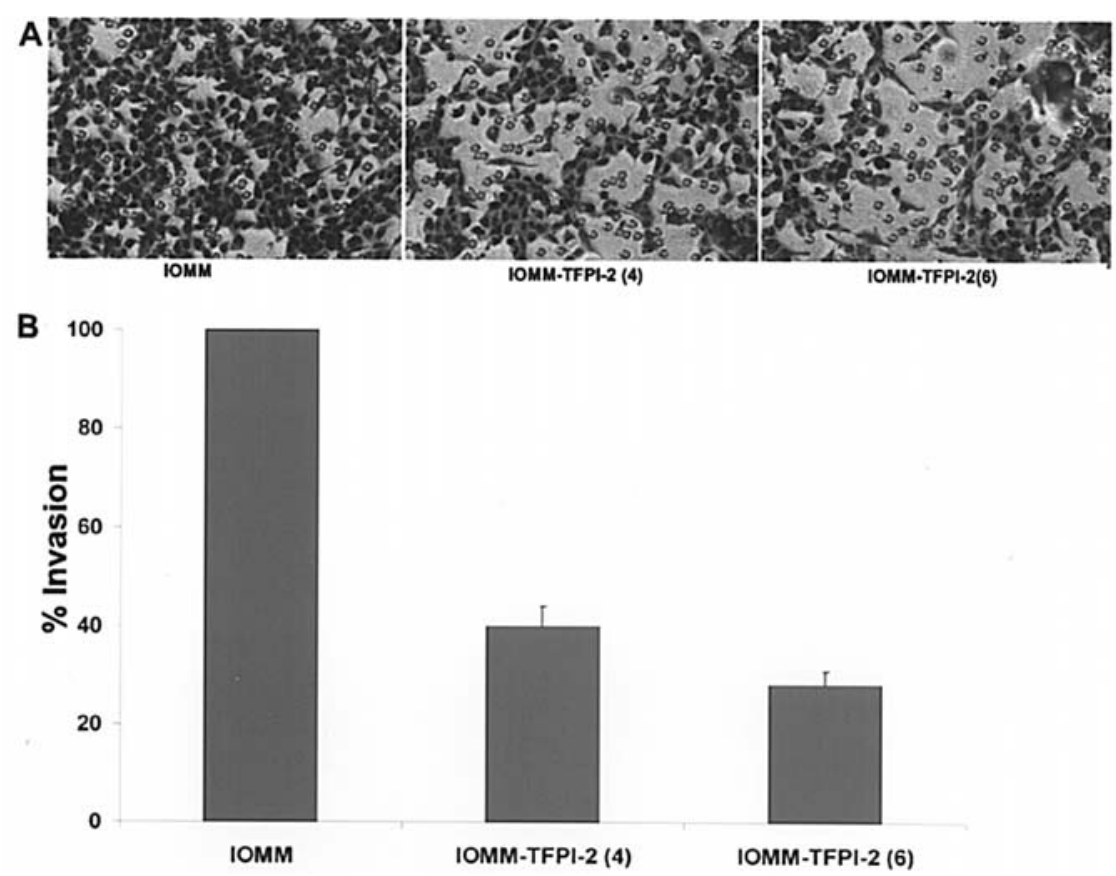

Figure 2. Matrigel invasion in IOMM-Lee parental and transfected cells. IOMM-Lee cells and TFPI-2-transfected cells $\left(1 \times 10^{6}\right)$ were layered on Matrigelcoated transwell inserts (8- $\mu \mathrm{m}$ pore size) and allowed to invade for $24 \mathrm{~h}$. Then, the filters were stained with Hema 3 (A) and invading cells were calculated as a percentage of total cells $(\mathrm{B})$.

A

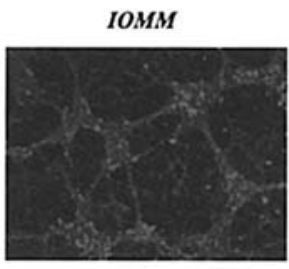

IOMM-TFPI-2 (4)

IOMM-TFPI-2 (6)
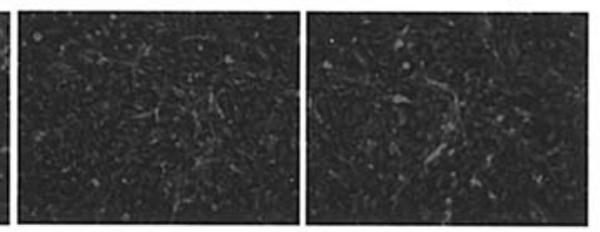

B

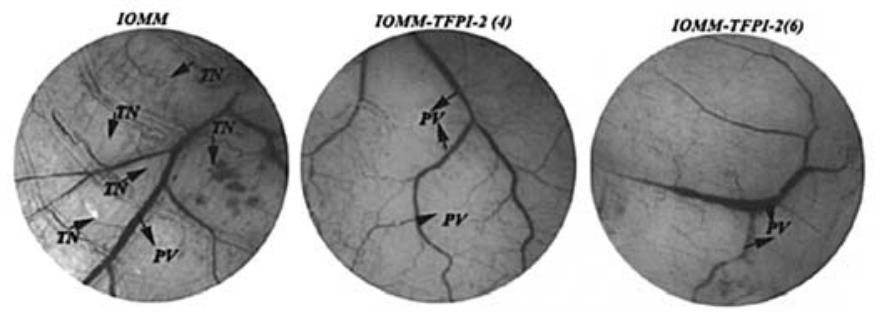

C

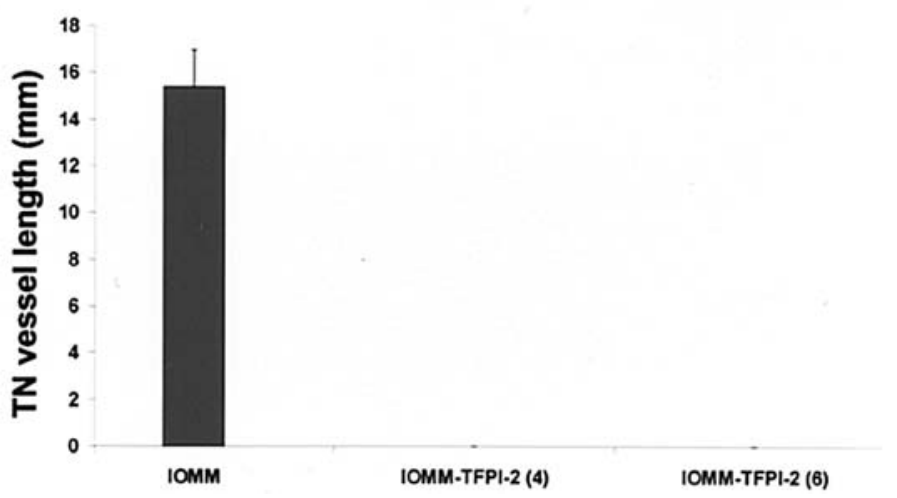

Figure 3. In vitro angiogenesis in IOMM-Lee parental and TFPI-2 transfected cells. IOMM-Lee parental and TFPI-2-transfected cells $\left(2 \times 10^{4}\right)$ were plated on 8 -well chamber slides and incubated overnight. Human microvascular endothelial cells (HMEC) $\left(4 \times 10^{4}\right)$ were added to the meningioma cells and co-cultured for 48-72 h. The co-cultures were then fixed and stained with factor VIII antibody and FITC-conjugated secondary antibody. The cells were observed under fluorescence microscopy for network alignment (A). IOMM-Lee parental and TFPI-2-transfected cells $\left(2 \times 10^{6}\right)$ were suspended in 100-150 $\mu 1$ of serum-free medium, injected into the diffusion chamber, and the opening was sealed and placed under the skin of nude mice for 10 days. The s.c. implanted chamber resulted in microvessel formation (as indicated by arrows) with curved thin structures (TN) arising from pre-existing vessels in IOMM-Lee parental cells. In contrast, no angiogenesis was observed in TFPI-2-transfected cells (B). Quantification of the in vivo vasculature was performed by measuring the length of the tumor induced vasculature $(\mathrm{TN})(\mathrm{C})$. 

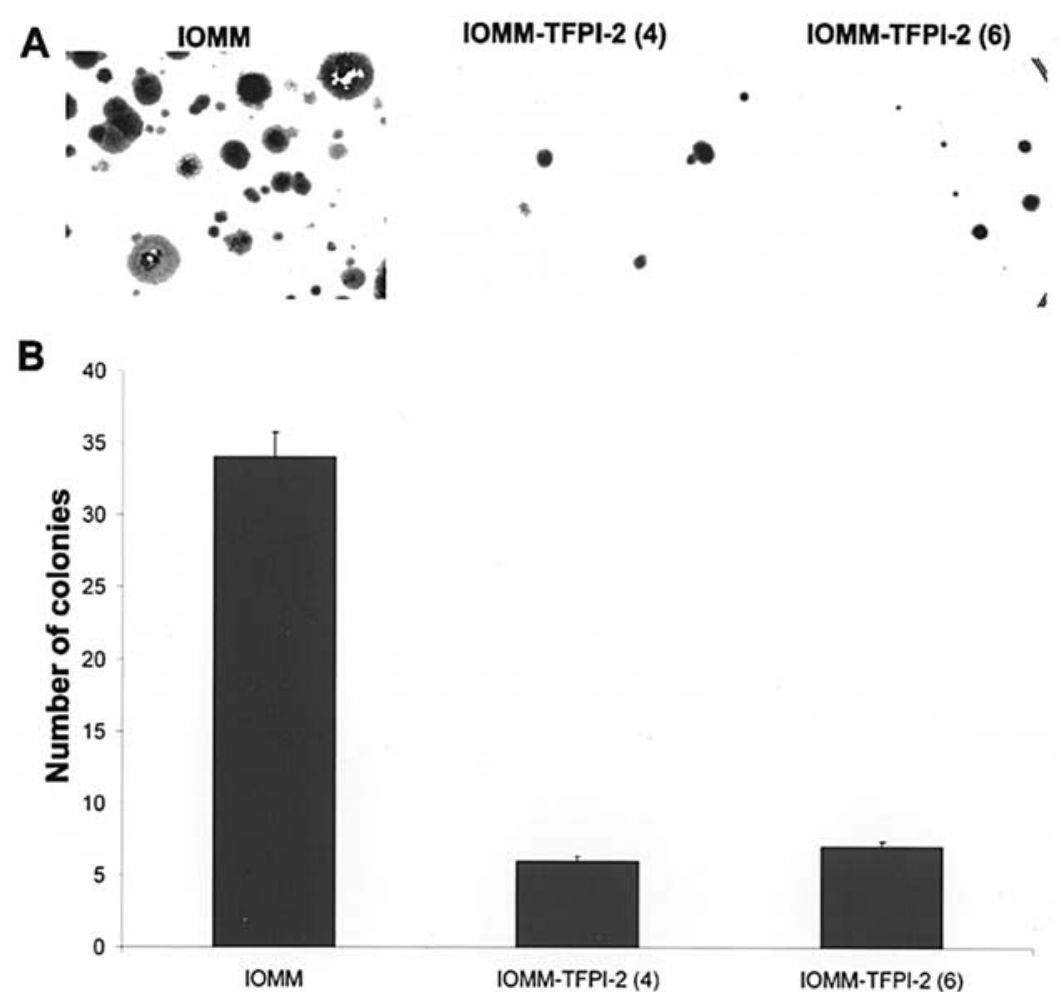

Figure 4. Colony formation in IOMM-Lee parental and transfected cells. IOMM-Lee parental cells and TFPI-2-transfected cells (4x $\left.10^{4}\right)$ were plated on 100-mm culture plates. The medium was changed every 3 days and, after 2 weeks, the colonies were fixed in methanol, stained with Hema 3 (A) and counted as a measure of clonogenicity (B).

the presence of thin, curvy structures emanating from preexisting vessels. In contrast, this structure formation was partially or completely inhibited in TFPI-2-transfected stable clones IOMM TFPI-2 (4) and IOMM-TFPI-2 (6) (Fig. 3B). Quantification of the vessel length of the tumor-induced neovasculature revealed a vessel length of $\leq 15 \mathrm{~mm}$ when IOMM cells were used (Fig. 3C). This study substantiates the in vitro results that TFPI-2 inhibits neovascularization.

TFPI-2 inhibits colony formation in IOMM-LEE cells. In vitro colony formation is used as a prognostic indicator in many cancers and drug studies. The size and number of colonies are keys to this assay. We used the colony assay to determine whether TFPI-2 inhibits colony formation. Cells $\left(4 \times 10^{3}\right)$ were seeded in 100-mm plates for 2 weeks. As seen in Fig. 4A, the number of colonies is significantly more in parental cells as compared to the very few colonies in TFPI-2-transfected cells (Fig. 4B).

TFPI-2 reduces intracranial tumor growth in nude mice. Our previous studies demonstrated that stable TFPI-2 transfectants reduced the growth of intracranial SNB19 tumors. We extended this in vivo study to IOMM-Lee cells. IOMM-Lee cells $\left(1 \times 10^{6}\right)$ were injected intracranially into female nude mice and sacrificed after 2 weeks. As expected, mice injected with parental meningioma cells formed brain tumors, whereas mice injected with stable clones showed reduced tumor growth. The sections were analyzed using H\&E staining. An examination by a neuropathologist revealed the presence of very small tumors in stable transfectants (Fig. 5).
TFPI-2 induced apoptosis in transfected cells. Apoptosis, or programmed cell death, plays a crucial role during development and tissue homeostasis and is usually cytochrome c-mediated or death receptor-mediated. Cytochrome c-mediated apoptosis is further mediated by caspase activation. Our previous studies demonstrated that TFPI-2 induces apoptosis in malignant human glioma SNB19 cells through the activation of caspases. In this study, restoration of TFPI- 2 in meningiomas induced increased expression of cytochrome c, BAX and cleaved caspase 3. In addition, expression of the X-linked inhibitor of apoptosis (XIAP) was reduced. GAPDH was used as a positive control to verify that protein loading was equal in all lanes (Fig. 6).

\section{Discussion}

In the present study, we restored TFPI- 2 expression in the malignant meningioma cell line, IOMM-Lee, by stably transfecting this cell line with a $0.7-\mathrm{kb}$ transcript in a sense orientation to study its role in tumor invasion and metastasis. As already established, many malignant tumors are highly invasive due to the secretion of proteases, including metalloproteinases $(22,23)$, serine proteinases $(24)$ and cysteine proteases, which degrade ECM and the basement membrane. TFPI- 2 is a kunitz-type serine proteinase inhibitor that plays a major role in ECM degradation during tumor cell invasion and metastasis, wound healing and angiogenesis. It is widely distributed and inhibits plasmin. Of note, TFPI-2 is underexpressed in tumors such as gliomas $(12,13)$ and overexpression of TFPI-2 inhibits the invasive potential of glioma (15) and choriocarcinoma (25). 

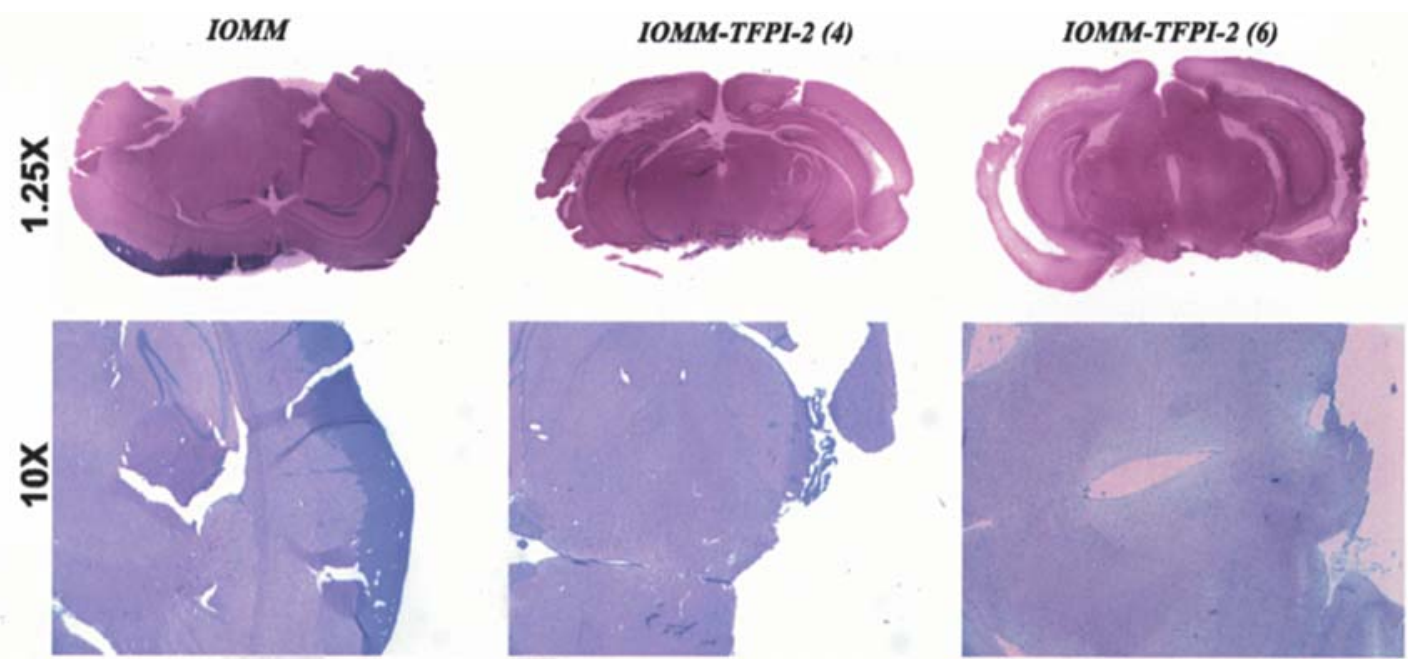

Figure 5. Intracranial injections of IOMM-Lee parental and transfected cells. IOMM-Lee parental and TFPI-2-transfected cells $\left(1 \times 10^{6}\right)$ were suspended in $10 \mu 1$ of serum-free medium and injected into 6-week old female athymic nude mice stereotactically. The mice were euthanized after 2 weeks and brains were extracted, fixed with formaldehyde and H\&E stained.

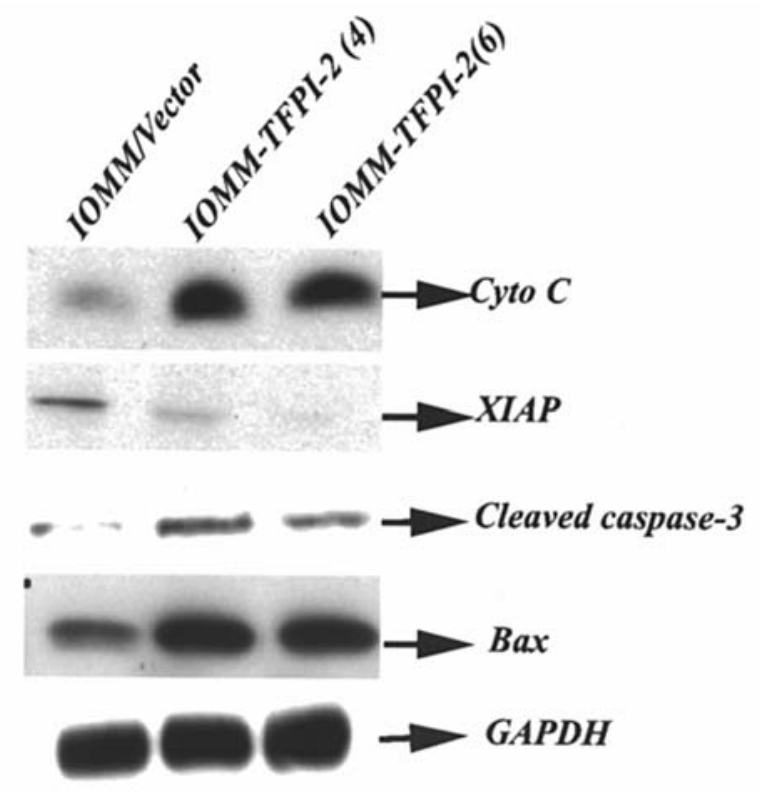

Figure 6. TFPI-2 signaling in IOMM-Lee and transfected cells. Total cell lysates were collected from IOMM-Lee parental and TFPI-2-transfectant cells. Total protein (20-50 $\mu \mathrm{g})$ was subjected to $12 \%$ SDS-PAGE electrophoresis and transferred onto nitrocellulose membranes. The membranes were later probed with cytochrome c, cleaved caspase 3, Bax and XIAP. GAPDH was used as an internal control to verify that equal amounts of protein were loaded in all lanes.

Analysis of normal brain and meningioma tissue samples revealed high TFPI-2 expression in normal brain and benign meningioma but no expression in malignant meningioma samples (Fig. 1). In addition, we observed overexpressed TFPI-2 protein in transfected IOMM-Lee cells (Fig. 2). Although the exact mechanism for this overexpression is unclear, it may be due to interference with mRNA transport or hybridization with cytoplasmic TFPI-2 mRNA. TFPI-2 directly inhibits plasmin, thereby preventing release of growth factors and activation of pro-MMPs responsible for ECM degradation. Recombinant TFPI-2 has been shown to inhibit plasmin at the surfaces of ECM and also to inhibit matrix degradation and matrigel invasion by HT1080 fibrosarcoma cells (2). In the present study, we used the Matrigel invasion assay to determine the effect of TFPI-2 in meningioma cells. The results demonstrated impaired invasion of IOMMLee cells in stable TFPI-2 transfectants (Fig. 3).

The ability to form new blood vessels is a characteristic feature of cancer cells. Tumor cells secrete both pro-angiogenic and anti-angiogenic factors (26). One such angiogenic factor is tissue factor, a cellular initiator of the extrinsic coagulation pathway, which is inhibited by TFPI- $2(3,4)$. Tissue factor aids in angiogenesis and tumor progression by upregulating the secretion of vascular endothelial growth factor (27) and UPAR (28) in gliomas, fibrosarcomas, melanomas and breast and pancreatic tumors (29-31). In the present study, capillary-like network formation was seen in co-cultures of IOMM-Lee and HMEC cells within 48 to $72 \mathrm{~h}$. However, capillary-like structure formation was inhibited in TFPI-2transfected stable clones (Fig. 4). In vivo studies in nude mice also showed inhibition of angiogenesis in transfected clones, further substantiating the results of the in vitro studies that TFPI-2 effectively inhibits new vessel formation (Fig. 5).

The colony-forming assay is used for measuring the functional capacity of stem cells or other cells as well as to investigate responses to growth factors, inhibitors and drugs. We used this assay to study the inhibitory effects of TFPI- 2 . The size and number of colony formations were impaired in TFPI-2-transfected clones (Fig. 6). Hembrough et al (32) reported that the anti-proliferative activity of TFPI is mediated by a VLDL receptor and that this receptor-ligand system may be a useful target for the development of new anti-angiogenic and anti-tumor agents. To test the anti-proliferative and antiangiogenic effects of TFPI-2, we injected IOMM-Lee parental and transfected cells intracranially into nude mice. The nude mice injected with transfected cells presented minimal growth, further supporting TFPI-2 as an anti-proliferative and antiangiogenic agent (Figs. 3 and 4).

Our previous studies showed that TFPI-2 is involved in apoptosis of human gliomas (33). Apoptosis is mediated by 
caspases, killer proteases that work in two distinct cascades (34). The first cascade is death receptor-mediated apoptosis through Fas and TNF receptors (35). The second is mitochondrial-dependent caspase cascade in which cytochrome c is translocated from the mitochondria into the cytoplasm (36). This cascade is regulated by changes in the expression of the Bax/Bcl-2 ratio. Knockout studies in mice have shown that the presence of at least one pro-apoptotic gene, Bax or Bak, is necessary for execution of apoptosis (37). Recent reports also showed that anti-apoptotic genes such as XIAP are upregulated in brain tumors and contribute to tumor progression $(38,39)$. In our study, we observed that cytochrome c, Bax and cleaved caspase 3 levels were elevated while the level of X-linked inhibitor of apoptosis (XIAP) was decreased in TFPI-2-transfected clones. These expression changes induced apoptosis in human malignant meningiomas (Fig. 6).

In conclusion, our findings indicate that TFPI- 2 is a novel anti-invasive, anti-angiogenic and pro-apoptotic agent. TFPI-2 inhibited angiogenesis and invasion and induced apoptosis in IOMM-Lee cells as seen in both the in vitro and in vivo studies. These studies demonstrate that TFPI-2 may have therapeutic value in the treatment of malignant meningiomas.

\section{Acknowledgements}

We thank Shellee Abraham for preparing the manuscript and Diana Meister and Sushma Jasti for manuscript review. This study was supported by N.I.H. Grants CA75557, CA92393, CA95058, CA116708, N.I.N.D.S. NS47699, and American Cancer Society (W.C.O.).

\section{References}

1. Miyagi Y, Koshikawa N, Yasumitsu H, Miyagi E, Hirahara F, Aoki I, Misugi K, Umeda M and Miyazaki K: cDNA cloning and mRNA expression of a serine proteinase inhibitor secreted by cancer cells: identification as placental protein 5 and tissue factor pathway inhibitor-2. J Biochem 116: 939-942, 1994.

2. Rao CN, Cook B, Liu Y, Chilukuri K, Stack MS, Foster DC, Kisiel W and Woodley DT: HT-1080 fibrosarcoma cell matrix degradation and invasion are inhibited by the matrix-associated serine protease inhibitor TFPI-2/33 kDa MSPI. Int J Cancer 76: 749-756, 1998.

3. Sprecher CA, Kisiel W, Mathewes S and Foster DC: Molecular cloning, expression, and partial characterization of a second human tissue-factor-pathway inhibitor. Proc Natl Acad Sci USA 91: 3353-3357, 1994.

4. Petersen LC, Bjorn SE, Olsen OH, Nordfang O, Norris F and Norris K: Inhibitory properties of separate recombinant Kunitztype-protease-inhibitor domains from tissue-factor-pathway inhibitor. Eur J Biochem 235: 310-316, 1996.

5. Rao CN, Liu YY, Peavey CL and Woodley DT: Novel extracellular matrix-associated serine proteinase inhibitors from human skin fibroblasts. Arch Biochem Biophys 317: 311-314, 1995.

6. Rao CN, Peavey CL, Liu YY, Lapiere JC and Woodley DT: Partial characterization of matrix-associated serine protease inhibitors from human skin cells. J Invest Dermatol 104: 379-383, 1995.

7. Rao CN, Gomez DE, Woodley DT and Thorgeirsson UP: Partial characterization of novel serine proteinase inhibitors from human umbilical vein endothelial cells. Arch Biochem Biophys 319: 55-62, 1995.

8. Udagawa K, Miyagi Y, Hirahara F, Miyagi E, Nagashima Y, Minaguchi H, Misugi K, Yasumitsu H and Miyazaki K: Specific expression of PP5/TFPI2 mRNA by syncytiotrophoblasts in human placenta as revealed by in situ hybridization. Placenta 19: 217-223, 1998

9. Lino M, Foster DC and Kisiel W: Quantification and characterization of human endothelial cell-derived tissue factor pathway inhibitor-2. Arterioscler Thromb Vasc Biol 18: 40-46, 1998.
10. Liu Y, Stack SM, Lakka SS, Khan AJ, Woodley DT, Rao JS and Rao CN: Matrix localization of tissue factor pathway inhibitor-2/ matrix-associated serine protease inhibitor (TFPI-2/MSPI) involves arginine-mediated ionic interactions with heparin and dermatan sulfate: heparin accelerates the activity of TFPI-2/ MSPI toward plasmin. Arch Biochem Biophys 370: 112-118, 1999.

11. Miyagi Y, Yasumitsu H, Eki T, Miyata S, Kkawa N, Hirahara F, Aoki I, Misugi K and Miyazaki K: Assignment of the human PP5/TFPI-2 gene to 7q22 by FISH and PCR-based human/rodent cell hybrid mapping panel analysis. Genomics 35: 267-268, 1996.

12. Konduri SD, Rao CN, Chandrasekar N, Tasiou A, Mohanam S, Kin Y, Lakka SS, Dinh D, Olivero WC, Gujrati M, Foster DC, Kisiel W and Rao JS: A novel function of tissue factor pathway inhibitor-2 (TFPI-2) in human glioma invasion. Oncogene 20: 6938-6945, 2001

13. Rao CN, Lakka SS, Kin Y, Konduri SD, Fuller GN, Mohanam S and Rao JS: Expression of tissue factor pathway inhibitor 2 inversely correlates during the progression of human gliomas. Clin Cancer Res 7: 570-576, 2001.

14. Lakka SS, Konduri SD, Mohanam S, Nicolson GL and Rao JS: In vitro modulation of human lung cancer cell line invasiveness by antisense cDNA of tissue factor pathway inhibitor-2. Clin Exp Metastasis 18: 239-244, 2000.

15. Konduri SD, Tasiou A, Chandrasekar N and Rao JS: Overexpression of tissue factor pathway inhibitor-2 (TFPI-2), decreases the invasiveness of prostate cancer cells in vitro. Int J Oncol 18: 127-131, 2001.

16. Akeyson EW and McCutcheon IE: Management of benign and aggressive intracranial meningiomas. Oncology (Williston Park) 10: 747-756, 1996.

17. Younis GA, Sawaya R, De Monte F, Hess KR, Albrecht S and Bruner JM: Aggressive meningeal tumors: review of a series. J Neurosurg 82: 17-27, 1995.

18. Laemmli UK: Cleavage of structural proteins during the assembly of the head of bacteriophage T4. Nature 227: 680-685, 1970.

19. Towbin H, Staehelin T and Gordon J: Electrophoretic transfer of proteins from polyacrylamide gels to nitrocellulose sheets: procedure and some applications. Proc Natl Acad Sci USA 76: 4350-4354, 1979.

20. Go Y, Chintala SK, Mohanam S, Gokaslan Z, Venkaiah B, Bjerkvig R, Oka K, Nicolson GL, Sawaya R and Rao JS: Inhibition of in vivo tumorigenicity and invasiveness of a human glioblastoma cell line transfected with antisense uPAR vectors. Clin Exp Metastasis 15: 440-446, 1997.

21. Mohanam S, Sawaya R, McCutcheon I, Ali-Osman F, Boyd D and Rao JS: Modulation of in vitro invasion of human glioblastoma cells by urokinase-type plasminogen activator receptor antibody. Cancer Res 53: 4143-4147, 1993.

22. Miyazaki K, Hattori Y, Umenishi F, Yasumitsu H and Umeda M: Purification and characterization of extracellular matrix-degrading metalloproteinase, matrin (pump-1), secreted from human rectal carcinoma cell line. Cancer Res 50: 7758-7764, 1990.

23. Umenishi F, Yasumitsu H, Ashida Y, Yamauti J, Umeda M and Miyazaki K: Purification and properties of extracellular matrixdegrading metallo-proteinase overproduced by Rous sarcoma virus-transformed rat liver cell line, and its identification as transin. J Biochem 108: 537-543, 1990

24. Koshikawa N, Yasumitsu H, Umeda M and Miyazaki K: Multiple secretion of matrix serine proteinases by human gastric carcinoma cell lines. Cancer Res 52: 5046-5053, 1992.

25. Jin M, Udagawa K, Miyagi E, Nakazawa T, Hirahara F, Yasumitsu H, Miyazaki K, Nagashima Y, Aoki I and Miyagi Y: Expression of serine proteinase inhibitor PP5/TFPI-2/MSPI decreases the invasive potential of human choriocarcinoma cells in vitro and in vivo. Gynecol Oncol 83: 325-333, 2001.

26. Folkman J: Antiangiogenic gene therapy. Proc Natl Acad Sci USA 95: 9064-9066, 1998.

27. Ollivier V, Bentolila S, Chabbat J, Hakim J and De Prost D: Tissue factor-dependent vascular endothelial growth factor production by human fibroblasts in response to activated factor VII. Blood 91: 2698-2703, 1998.

28. Taniguchi T, Kakkar AK, Tuddenham EG, Williamson RC and Lemoine NR: Enhanced expression of urokinase receptor induced through the tissue factor-factor VIIa pathway in human pancreatic cancer. Cancer Res 58: 4461-4467, 1998.

29. Hamada K, Kuratsu J, Saitoh Y, Takeshima H, Nishi T and Ushio Y: Expression of tissue factor correlates with grade of malignancy in human glioma. Cancer 77: 1877-1883, 1996. 
30. Mueller BM, Reisfeld RA, Edgington TS and Ruf W: Expression of tissue factor by melanoma cells promotes efficient hematogenous metastasis. Proc Natl Acad Sci USA 89: 11832-11836, 1992.

31. Nakagawa K, Zhang Y, Tsuji H, Yoshizumi M, Kasahara T, Nishimura H, Nawroth PP and Nakagawa M: The angiogenic effect of tissue factor on tumors and wounds. Semin Thromb Hemost 24: 207-210, 1998.

32. Hembrough TA, Ruiz JF, Papathanassiu AE, Green SJ and Strickland DK: Tissue factor pathway inhibitor inhibits endothelial cell proliferation via association with the very low density lipoprotein receptor. J Biol Chem 276: 12241-12248, 2001.

33. Tasiou A, Konduri SD, Yanamandra N, Dinh DH, Olivero WC, Gujrati M, Obeyesekere M and Rao JS: A novel role of tissue factor pathway inhibitor-2 in apoptosis of malignant human gliomas. Int J Oncol 19: 591-597, 2001.
34. Nicholson DW and Thornberry NA: Caspases: killer proteases. Trends Biochem Sci 22: 299-306, 1997.

35. Nagata S: Apoptosis by death factor. Cell 88: 355-365, 1997.

36. Kluck RM, Bossy-Wetzel E, Green DR and Newmeyer DD: The release of cytochrome $\mathrm{c}$ from mitochondria: a primary site for Bcl-2 regulation of apoptosis. Science 275: 1132-1136, 1997.

37. Eischen CM, Rehg JE, Korsmeyer SJ and Cleveland JL: Loss of Bax alters tumor spectrum and tumor numbers in ARF-deficient mice. Cancer Res 62: 2184-2191, 2002.

38. Isenmann S, Engel S, Gillardon F and Bahr M: Bax antisense oligonucleotides reduce axotomy-induced retinal ganglion cell death in vivo by reduction of Bax protein expression. Cell Death Differ 6: 673-682, 1999.

39. La Casse EC, Baird S, Korneluk RG and MacKenzie AE: The inhibitors of apoptosis (IAPs) and their emerging role in cancer. Oncogene 17: 3247-3259, 1998. 